he became acquainted only much later through Darwin's books. Thus it appears that between 1840 and 1850 , in three at least of the six universities of Prussia, Sprengel's work had fallen into the most complete oblivion. Now it is improbable in the highest degree that the several professors of natural history in these universities should have ceased, unanimously and at the very same time (184I) to teach what, between 1830 and 1840 , they had taught "as well known facts of the highest importance." Hagen's statement, therefore, needs sime further proof before it can be accepted.

If in Germany Sprengel's discoveries had been "well known to every naturalist during the whole century," the opinion that his treatise had been unduly neglected until it was, as it were, re-discovered by Darwin, could never have prevailed, as it appears to do, among German botanists, and Prof. Eduard Strasburger could never have written the following lines, with which I may appropriately conclude this letter: "Until I860 and some years afterwards in any catalogue of old botanical books, the work of Conrad Sprengel, published in 1793, 'I)as entdeckte Geheimniss der Natur im Bau und in der Befruchtung der Blumen' might be found at the price of about 15 sgr. (Is. $6 d$.), and I myself bought it there at that price as a curiosity, for the sake of its strange title. In the 22oth catalogue of Friedlander (1873) the price of the same book is 3 thlr. 20 sgr. (IIs.) This rise in the price of Sprengel's book shows very strikingly the change through which in the meantime it has passed in our appreciation. For only during the last ten years, after it had remained wholly unnoticed for nearly seventy years, the old book has come to be duly valued. It was Charles Darwin, who by his excellent book on Orchids . . . revived the questions treated by Sprengel " (Fenaer Literatur Zeitung, I874, article 140.) FRITZ MülleR

Blumenau, Santa Catharina, Brazil, December 15,1883

\section{Diffusion of Scientific Memoirs}

Prof. TAIT appears to have misunderstood my object in writing the letter published in your issue of January 24 (p. 287). It refers distinctly to his letter of December 27 , and not directly to the review which began the correspondence. In that letter Prof. Tait stated publicly that he had nt received certain publications of the Cambridge Philosophical Society. I desired, as secretary, to explain that it was not due to the neglect of the officers of the Society. He also says :- "NATURE would do a real service to science by collecting statistics as to the numbers of different centres .... at which the Transactions of various scientific societies were freely accessible in 1883 (say) and also in I853." It was in my power to give the statistics for "Transactions or Proceedings or both" for the year 1883; in answer to part of Prof. Tait's suggestion I did so. There is no reference in my letter to the year 1854 , so that Prof. Tait is not correct in stating (NATURE, January 3I, p. 3II) that the question between us is, "What was the state of matters in 1854 ?" The year 1869 was the earliest for which, with the data ready to hand, I could obtain the numbers, I therefore gave statistics for that year in addition; I had no knowledge of what may have been the case in 1854, and I said nothing about it. Prof. Tait referred to a malady and suggested a cure. I merely wished to show that the cure had already been applied. My remarks were addressed solely to that point, and were not "beside the question." Prof. Tait, in your last issue, has an elaborate argument to prove that about one-third of the centres receiving publications receive Proceedings only. In this he is entirely mistaken. At present the number of such centres is 6 ; in 1854 it was o. The history of the case is as follows. Until the year 1843 the Cambridge Philosophical Society published no Proceed ings. Between that year and 1864 short accounts of the papers read and of the discussions were published in the Phil. Mrg., and separate copies were supplied to the Society. In I864 these were collected, and form vol, i. of the Proceedings. At the time they were not circulated separately; circulation was given them in the Phil. Mag. In that year the arrangement with the Phil. Mag. came to an end, and notices of the same kind were printed by the secretaries and distributed to resident Fellows. Almost without an exception all the important papers published by the Society appeared in the Transactions. There was no need therefore to circulate Proceedings, and it was not done. This practice was continued up to 1876 , whan the second volume of the Proceedings was closed, and a new sy:tem begun. Thus up to 1876 all centres re- ceiving publications necessarily received Transactions, and as a matter of fact nothing else. A few copies of vols. i. and ii. of the Proceedings have since been issued. Vol. iii. of the Proceedings was commenced in 1876 , and both it and succeeding volumes contain in full the shorter or the less important communications made to the Society, as well as abstracts of matter published in full in the Transactions. Vols. iii, and iv., then, of the Proceedings have, as a general rule, been sent with the Transactions, and the centres have usually, since 1876 , received both. Within the last few years, however, 6 centres have been added to the list which receive the Proceedings only. Thus in 1883 (omitting the honorary Fellows) II4 centres received Transactions only, or Transactions and Proceedings, in most cases the latter, and 6 received Proceedings only; while in 1853 all the publications distributed were 7 ransactions. I do not pretend to know what the number of centres was at that date, and my first letter made no direct reference to it. Nothing in that letter, however, supports the arguments adduced by Prof. Tait to prove that "it follows from Mr. Glazebrook's data that the number of centres in I 854 must have been about 40 only."

$$
\text { R. T. Glazebrook, }
$$

Secretary of the Cambridge Philosophical Society

Cambridge, February 4

\section{Brooks' Comet}

I SEND you a sketch of Brooks' comet, in which an attempt is made to represent a remarkable change which took place in the comet about January I3. On that evening the welldefined and almost circular envelope which is represented in the figure was entirely wanting when the comet was seen on previous occasions. The nucleus was much more condensed and star-like than at any time before. The envelope was of neariy unifnrm brightness, with a perfectly defined outline, which was easily measured. It seemed to be produced by two fan-shaped emanations from the nucleus, which, curving backward toward each other, met at the outer edges, leaving a darker elliptical space on each side of the nucleus, the space on the north side being the darker, and the preceding fan-shaped portion having an extension on the north side. A line drawn through the middle of the dark spaces would be perpendicular to the axis of the tail.

The diameter of this envelope was $\mathrm{I}^{\prime} \mathrm{2O}^{\prime \prime}$, while the diameter of the outer nebulous envelope, as far as it could be readily traced, was about $6^{\prime} 9^{\prime \prime}$. The spectroscope showed a bright continuous spectrum, which was surprisingly strong in the red, which completely maskerl any lines. As the comet had not been seen here for several days previous to the $13^{\text {th }}$, this appearance may have been of considerable duration. Clouds prevented another view until January $\mathrm{I} 7$, when the inner envelope had entirely lost its sharp outline, and the following portion had disappeared, leaving a corresponding dark space, while the preceding portion had increased its angular dimensions and revolved through an angle of about $60^{\circ}$.

This is the appearance it presented, though the change may have occurred in a very different manner. The 26 .inch equatorial did not bring out any additional details. The distance from the following side of the nucleus to the outer edge of the inner envelope was about $32^{\prime \prime}$, whereas it had been $40^{\prime \prime}$ on the I $3^{\text {th }}$, taking half the diameter of the envelope on that occasion to represent the corresponding measurement on the 17 th.

A very marked increase in the length of the tail of the comet occurred between December 27 and 28 . For about one-third of its length the tail was broad and fairly uniform in brightness; from the middle of this broad portion issued two long bright streams, one being longer and brighter than the other. The total length was about $4^{\circ}$.

Naval Observatory, Washingtcn, January 19

\section{" Mental Evolution in Animals"}

THE appearance of Mr. Romanes' new book with the above title reminds me of a reference in his work on "Animal Intelligence" to an observation of my own. I have intended for at least twelve months past to write you about the matter, but as Mr. Romanes' new book is practically a continuation on his former work, you will probably not conclude that I have procrastinated too long.

On page 25I of "Animal Intelligence" $\mathrm{Mr}$. Romanes quotes my story of a skate in the Manchester Aquarium. The fish in 